\title{
COMPLICAÇÕES RELACIONADAS ÀS OSTEOTOMIAS SAGITAIS DOS RAMOS MANDIBULARES
}

Rafael SANTOS, Matheus Sabóia MARCONDES, Delson João da COSTA, Nelson Barbosa REBELLATO, Paulo Roberto MÜLLER

A osteotomia sagital do ramo mandibular é provavelmente o procedimento cirúrgico mais utilizado para correção de deformidades da mandíbula. Uma de suas vantagens é a possibilidade de avanços e recuos mandibulares. As complicações trans-operatórias são mais freqüentes como decorrência de não observância de detalhes da técnica cirúrgica ou de falhas de avaliação da anatomia do paciente. Segundo O'RYAN (1989) elas são divididas em separações ósseas desfavoráveis, hemorragias, lesões nervosas, mau posicionamento do segmento proximal e dificuldades técnicas menores. Complicações em cirurgias ortognáticas podem ocorrer, e efetivamente ocorrem, com praticamente todos os cirurgiões envolvidos no tratamento de pacientes portadores de deformidades buco-maxilo-faciais. Um amplo entendimento das bases biológicas para o planejamento do procedimento, a correta avaliação da natureza da deformidade, a probabilidade de ocorrência de um determinado tipo de complicação antes, durante ou após a cirurgia, os mecanismos para a prevenção e o correto tratamento destas, se constituem na essência do conhecimento necessária para o correto tratamento dos pacientes. Este trabalho tem o objetivo de realizar uma revisão de literatura ilustrando algumas complicações que podem ocorrer durante a osteotomia dos ramos mandibulares e a maneira encontrada para solucionar esses problemas. 